\title{
The Exploration of Tennis Culture under the Perspective Campus Sports Culture
}

\author{
Hezhen Wang ${ }^{1, \text { a }}$ \\ ${ }^{1}$ Hubei University of Automotive Technology, Shiyan, Hubei Province, China \\ a51072630@qq.com
}

Keywords: Tennis Culture, Universities, Sports Culture, Exploration

\begin{abstract}
Under the impetus of the national fitness campaign, tennis sport with its elegant and fashionable features gradually are loved very much by college students. This article has analyzed the tennis culture and the internal relations of college campus sports culture. It is thought tennis culture construction is to improve and promote the development of campus sports culture and even the entire campus culture, the mutual fusion under certain conditions can be the forerunner of national fitness.
\end{abstract}

\section{Introduction}

College campus culture in universities as the carrier, with material and spiritual wealth created by teachers and students, for specific performance. To disseminate and popularize tennis education in colleges and universities is the most important ways of tennis sports and culture, its movement characteristics of elegance, fashion, health also is generally favored by college students at present, the most colleges and universities have opened tennis lessons, or to carry out all kinds of tennis activities, create a good atmosphere to promote sport, become an important part of campus sports culture and strong support [1].

\section{The characteristics of college campus sports culture}

College campus sports culture is the certain social politics, economy, education, culture, sports and other conditions as the foundation, to colleges and universities as the main body, staff and students of colleges and universities sports environment and the needs of students synthesize. College campus sports culture is the campus characteristics and healthy living atmosphere of a kind of mass culture, has a higher level and grade, it combines fitness, recreation, entertainment, spreading culture functions in one, is an important content of college students' cultural life, has the following seven major characteristics [1].

Directional. The goal of higher education in our country is to cultivate virtue, wisdom, body, beauty comprehensive development have ideal, have moral, culture, have discipline high-level talents to adapt to the social development [1]. The school orientation determines the college campus sports culture activities must obey and serve the direction, therefore, sports in colleges and universities must according to the needs of the higher education to cultivate qualified talents to the construction of colleges and universities sports culture, sports culture as a way of thinking, behavior and way of life, teach students in science, health, civilization of sports activities, promotes the high grade of campus sports culture, inspires students physical fitness scientifically, set up the correct outlook on life, values, moral values and patriotism, towards a healthy campus sports culture, and to the right track.

High level. Of the vast number of teachers and students in colleges and universities is the main part of the campus sports culture activities, the overall high knowledge level, determines the grade of university sports culture construction is high, the appreciation level is high, high rational knowledge, strong consumer consciousness, activity design standard of higher level features [1]. As a batch of standing on the social and cultural front, continuously explore and development to create new culture of the group as a present, and future of high-level talents, the main body of college campus sports culture has no longer satisfied with simple running, play ball, such as the traditional exercise program, 
they are eager to have a modern high-level campus sports culture, the spirit of a culture, sport becomes one of the products, to meet the growing demand for sports culture.

Highlight the teaching emphasis and difficulty. The use of multimedia can better outstanding teaching important points and break through the teaching difficulties in the traditional teaching mode, the key points and difficulties in the teaching goal of professor entirely by teachers through verbal and written communication, personal due to restricted by way of simplification, students' cognitive level cannot be guaranteed for knowledge, and modern multimedia teaching can better solve this problem [2]. The use of $2 \mathrm{~d}$ and $3 \mathrm{~d}$ animation technology and video technology, make the abstract and profound knowledge information simplification, visualizations, shortens the distance between students and objective physical, decomposition of the complexity of knowledge information, also shortened the knowledge information from image to abstraction, in the student mind again from abstraction to image processing, fully convey the teaching intention, highlight the teaching focus, so as to maximize the guarantee of the realization of teaching goals.

The mass characteristics. College campus sports culture is a prominent function it entertaining, why it has such a function, is that it is easy to participate in, the characteristics of people happy. Generally speaking, college sports focuses on people's physical and mental needs and the satisfaction of the emotional desire, not a complex skill, with profound philosophical and profound culture conditions of the participants were asked to, but in general, entertaining, recreational, gameplay mode of activities to cater to participate in the object, so that they can be directly in the activities of the main body of pleasant emotional experience [2]. Therefore, to make it naturally produced great attraction, attract the vast majority of teachers and students actively participate in, no matter in the vast space, or on the persistence of time, the value of sports culture is the envy of other campus culture.

Diversity. College sports and the combination of university cultural education, can produce the diversity of the campus sports culture activities. In addition to a variety of competitive sports, fitness sports, entertainment and leisure sports and spectator sports activities outside, also include the above all kinds of sports activities and campus culture mutual infiltration, interweave to show students to a variety of cultural activities, such as sports photography, sports \&news, knowledge of sports competitions, sports, small sports production, small inventions, various sports cultural activities such as survival [3].

Practical. College campus sports culture is the combination of culture and campus culture of colleges and universities, it should reflect the essential characteristic of sports practice. In addition, a student is dynamic stage in life, desire strong hands-on experience, students have a purpose, organized to create conditions to carry out all kinds of popular sports activities, in practice, experience the fun of sports, value, cultivate the spirit of good sportsmanship and sports, make sports organic ground combines theory and practice, so as to achieve the goal of the all-round development [3].

Open. With the coming of information society, the increase of the campus information sources, the majority of students of the college sports rely less and abroad and all kinds of social sports outside form, management way to begin to enter the university campus, university students' sports began to flow to the outside world, has become an increasingly important social function of sports education [1]. Therefore, the construction of campus sports culture in colleges and universities must also be adapted to this kind of openness, to build with characteristic of Chinese college campus sports culture.

\section{The characteristics and connotation of tennis culture}

The characteristics of tennis culture. Tennis has a long history, conceived in France, was born in Britain, began to spread and form climax in the United States, now prevalent throughout the world. Tennis eventually formed "containing different times in different historical period features" of the unique connotation.

First of all, the tennis culture is a kind of state of matter. Tennis activities is important material form of self-perfection, the self-development. By tennis exercise, can make participants' body form and function improved, gradually the lifelong sports and nationwide fitness. Second, the tennis 
culture is a kind of spirit culture. Tennis movement itself has distinctive features: civilization, elegant, independent, open, romantic, leisure, fashion, attaches great importance to the etiquette and full of personality, rigorous and innovative rules [4]. Third, the tennis culture is a kind of system culture. Tennis competition system and rules for participants is a kind of constraint and regulate. Fourth, the tennis culture is a kind of behavior. Tennis etiquette players, the players and the behavior of the other participants, the training tennis participants good behavior literacy has a positive role.

Tennis culture connotation. Tennis culture movement of ideas, system, behavior and the sum of material culture, including tennis system of knowledge, skills, and conduct, etc. These features and campus sports culture advocated by internal consistency. Not only that, the connotation of culture has a subtle influence on the college students and role. Tennis culture and, therefore, the university campus sports culture is mutual promotion, complementary relationship [5]. Sports culture is an important part of college campus culture, in sports colleges and universities, sports culture is dominant and core of campus culture. Tennis culture from belongs to the sports culture, the development of campus sports culture can guide and stimulate the development of tennis culture inevitably.

In the climate of leisure and fitness, campus physical education occupies a considerable proportion of, many college students in the course of an active part in all kinds of sports, fitness, cheerful body and mind. As the "hot" tennis growing, tennis with her youth, fashion, move feeling and elegant, full of personality, quickly attracted a large number of students, with their unique feeling experience with strict rules, tennis competition, norms of etiquette and the spirit of solidarity and collaboration, with its unique perspective interpretation and understanding of tennis culture [5]. Due to the increase in population of campus tennis with rising, thus more widely promote the development of tennis sport and inheriting the profound tennis culture, under the guidance of campus sports culture, can make its form campus tennis culture with the characteristic of campus culture.

Tennis culture and the construction of college campus sports culture. College tennis culture because of the particularity of its own part of the high level of the college sports culture, at the same time, through the development of tennis sport in colleges and universities, tennis course open to further enrich their sports culture, promote sports culture atmosphere [6]. At the same time, the development of university sports culture is at the system level to promote the development of tennis culture, the two promote each other, rely on each other.

Tennis cultural spirit is the core content, has a guiding role to play. Tennis on their own in the development process of formation of the unique culture of college students had a great effect for the construction of spiritual civilization and in the tennis player's unity and cooperation, beyond the self, not speaking out of turn to give up the spirit of the spirit and campus style of study, teaching style and work style.

Tennis material culture is further complement of college campus culture. Tennis require specific location equipment, if there is no tennis venues and equipment is in tennis [6]. Tennis venue, the construction of the equipment is to open tennis lessons, prerequisite to hold activities such as tennis. Tennis venue for the construction of the equipment, the development of tennis culture on campus has played a positive role in promoting. Tennis facilities is the hardware guarantee of the tennis teaching smoothly, relationship to the degree of tennis school campus culture development.

Tennis culture contained in the system of the tennis game rules and the established etiquette culture, these all can become a part of the system culture. In the process of participation in tennis athletes to the restraint of the system and the rules and norms, for athletes to build an ideal game atmosphere, and the atmosphere for athletes to develop the traditional virtues of honesty, fair competition plays a great role. And the game rules and regulations, with the purpose of the university sports management system with the same are in order to standardize the behavior of students.

Tennis etiquette cultural norms of the players and spectators in the sports behavior in the process of China since ancient times known as "paradise" the laudatory name, are of the utmost importance to etiquette behavior. In tennis there is all the people and things "to" respect the tennis court that a basic code of conduct, which requires athletes to respect the court's rival, the staff, service personnel, fan, etc., these are all tennis culture manifests the elegant behavior civilization, have to say that tennis 
etiquette culture with a strong penetration and influence of specification in can promote college students' behavior and etiquette, form good behavior.

Tennis culture to enhance the campus sports culture. Tennis is more popular now, spread fast fashion movement, was deeply loved by students, its cultural construction is to promote and advance the campus sports culture and an important link in the whole campus culture development [6]. Sports culture is strong bones and muscles, increase knowledge, feelings, strong will, eventually reach physically the best state. Tennis sport strength, speed, strength and ability to respond to have higher requirements for participants, participants tennis can exercise the coordination of the body, show their personality, enhance the ability of strain and doing things; Pay attention to the coordination and cooperation of team, tennis in tennis and can understand the importance of teamwork, improve the win-win consciousness; Tennis has strict rules and regulations, competition is intense, the tennis movement is beneficial to cultivate college students' enterprising spirit in the competition and self-discipline consciousness.

Campus tennis culture is closely related to campus life, it is the student as the main body, in the process of physical education and extra-curricular activities, in the campus, for living space, and with the spirit of the campus through each other. Tennis culture to cultivate college students' civilization thoughts and behaviors.

\section{Summary}

Reflected in the movement speed, strength and competition aroused interest of modern college students, and elegant tennis culture everywhere embodies the civilization also satisfies the desire to college students for the pursuit of civilization and progress. Nowadays tennis on college campuses in the overall development situation is good, hope to pay more attention to some of the construction of campus tennis culture, makes the tennis movement the most colorful part of campus sports culture.

\section{References}

[1] H.T. Shi, Tennis culture influence on the university campus sports culture research, Journal of Jilin Engineering Technology Normal University, vol.42, pp.43-47,2012

[2] B.Z. Liang and X. Li, For our country to carry out the investigation on the present situation of ordinary university students' sport, sports science and technology in Shandong, vol.13, pp.21-27,2004.

[3] F.F. Yang, Sh.H. Lei, The social culture of tennis sport, Sports and Science, vol.8, pp.66-71, 2005.

[4] Y.F. Xu, The theory of college students' tennis and physical and mental health, Journal of Zhejiang Normal University, vol.65, pp.4-9, 2003.

[5] P.X. Lee, Analyze the tennis culture influence on college students, Sports world academic, vol.12, pp.12-18, 2006.

[6] J. Sun, Shandong university tennis sports development present situation analysis and countermeasure research, Journal of Jilin institute of sport, vol. 2, pp.41-47, 2007 